www.jmscr.igmpublication.org

Index Copernicus Value: 79.54

ISSN (e)-2347-176x ISSN (p) 2455-0450

crossrefDOI: https://dx.doi.org/10.18535/jmscr/v7i2.181

\title{
Functional Outcome of Osteotomy and Telescopic intramedullary nailing in paediatric cases of Osteogenesis imperfecta with Long bone Deformities
}

\author{
Authors \\ T. Satish Chandra Reddy ${ }^{1}$, Chennakesava Rao Sajja ${ }^{2}$ \\ ${ }^{1,2}$ Junior Resident, Department of Orthopaedics, King George Hospital, Andhra Medical College, \\ Visakhapatnam, India \\ Email: dr.satishchandrareddy@gmail.com,kesav4u6@gmail.com
}

\begin{abstract}
Introduction: The main feature of osteogenesis imperfecta is an excessive fragility and deformability of the bones owing to reduced mass and bone quality. This leads to angular deformity and frequent fractures. These fractures usually heal normally, and malunion is a common complication with conservative management.

Aims and Objectives: To study the outcome of osteotomy and telescopic intramedullary nailing in paediatric cases of Osteogenesis imperfecta with deformities in long bones.

Methods and Methodology: 6 cases of Osteogenesis imperfecta with deformities of long bones of lower limb were included in the study. All were treated using Telescopic intramedullary nailing after corrrection of deformity by osteotomy. Results were evaluated after 1 year of follow up by using radiological evaluation and functional usage of the limb.

Results: Radiological fracture healing was noticed at 14 weeks in all cases. Allowed full weight bearing after radiological fracture healing. Patients were able to walk without any aids after 6 months. One case had recurrence of deformity at lower tibia after 1 year of follow up.

Conclusion: The staged surgical stabilization performed allows for simultaneous correction of deformities and fracture healing resulting in rapid mobilization and better functional outcome.

Keywords: Osteofenesis imperfect, deformity correction, telescopic nailing.
\end{abstract}

\section{Introduction}

Osteogenesis imperfecta (OI) is a rare inherited disorder of connective tissue with the common feature of fragile bones. It is caused by mutations in the COL1A1, COL1A2 genes, which encode the $\alpha-1$ and the $\alpha-2$ chain of type I precollege. Other mutations also identified in leucine prolineenriched proteoglycan ${ }^{1}$, cartilage associated protein, peptidyl-prolylisomerase B genes. Incidence is 1:20,000 and occurs in all races and ethnicity. Mostly autosomal dominant disorder, but AR.

The main feature of osteogenesis imperfecta is an excessive fragility and deformability of the bones owing to reduced mass and bone quality. This leads to angular deformity and frequent fractures. It is characterized by multiple and recurrent fractures, which are intrauterine or perinatal or post-natal. Other features include blue sclera, otosclerosis with hearing loss, high arched palate, 
hyperlaxity of ligaments and skin, "dentinogenesis imperfecta" (defective dentition), scoliosis and growth retardation, Wormian bones could also be seen on skull X-ray. Intelligence is not affected.

Sillence et al., classification is the most helpful in prognosis and genetic counselling.

I able 1. Sillence UU, Uanks UM: I he ditterentiation of genetically distinct varletles of osteogenesIs Impertecta in the newborn period, Clin Res 26:178, 1978

\begin{tabular}{|c|c|c|c|c|c|c|}
\hline Type & Inheritance & Bone fragility & $\begin{array}{l}\text { Deformity of } \\
\text { long bones }\end{array}$ & $\begin{array}{l}\text { Growth } \\
\text { retardation }\end{array}$ & Spine & Incidence \\
\hline $\mid A$ & Autosomal dominant & $\begin{array}{l}\text { Variable, less } \\
\text { severe than } \\
\text { mostly }\end{array}$ & Moderate & Short stature & $\begin{array}{l}\text { Scoliosis and } \\
\text { kyphosis in 20\% }\end{array}$ & $1 / 30.000$ \\
\hline $\mathbb{B}$ & Autosomal dominant & $\begin{array}{l}\text { Variable, less } \\
\text { severe than } \\
\text { mostly }\end{array}$ & moderate & Short stature & $\begin{array}{l}\text { Scoliosis and } \\
\text { kyphosis in 20\% }\end{array}$ & $1 / 30.000$ \\
\hline$\|$ & Autosomal recessive & Very extreme & $\begin{array}{l}\text { Crumbled } \\
\text { bone }\end{array}$ & Unknown & - & $1 / 62.000$ \\
\hline$\|$ & Autosomal recessive & severe & $\begin{array}{l}\text { Progressive } \\
\text { bowing of the } \\
\text { long bone }\end{array}$ & $\begin{array}{l}\text { Severe, } \\
\text { smallest of all } \\
\text { patients }\end{array}$ & kyphoscoliosis & Very rare \\
\hline IVA & Autosomal dominant & Moderate & Moderate & Short stature & kyphoscoliosis & unknown \\
\hline IVB & Autosomal dominant & Moderate & moderate & Short stature & kyphoscoliosis & unknown \\
\hline
\end{tabular}

Diagnosis can be made clinically. Radiographic support and confirmation by collagen analysis of skin fibroblast culture or blood DNA analysis may be necessary in some cases. At present there is no cure for Osteogenesis imperfecta. Management is by multidisciplinary approach, mainly Surgery, physiotheraphy and rehabilitation. However, pharmacological therapy with bisphosphonates have shown good prospects.

This study was done because of its rarity, to review the literature and to highlight the challenges in its management.

\section{Aims and Objectives}

To study the outcome of osteotomy and telescopic intramedullary nailing in paediatric cases of Osteogenesis imperfecta with deformities in long bones.

\section{Patients and Methods}

During November 2016 and August 2018 in King george hospital, visakhapatnam 6 cases of Osteogenesis imperfecta were identified and included in the study for further evaluation. All cases are of type one Sillence.

All were diagnosed based on the clinical features, radiological evaluation and collagen analysis. Complete clinical, radiological and Labouratory evaluation done. Parents were thoroughly counselled about the condition and proposed line of Management. A decision to operate (osteotomy and telescopic nail fixation) was taken. Closed wedge osteotomy was performed and telescopic intramedullary nailing done in an anterograde manner. 


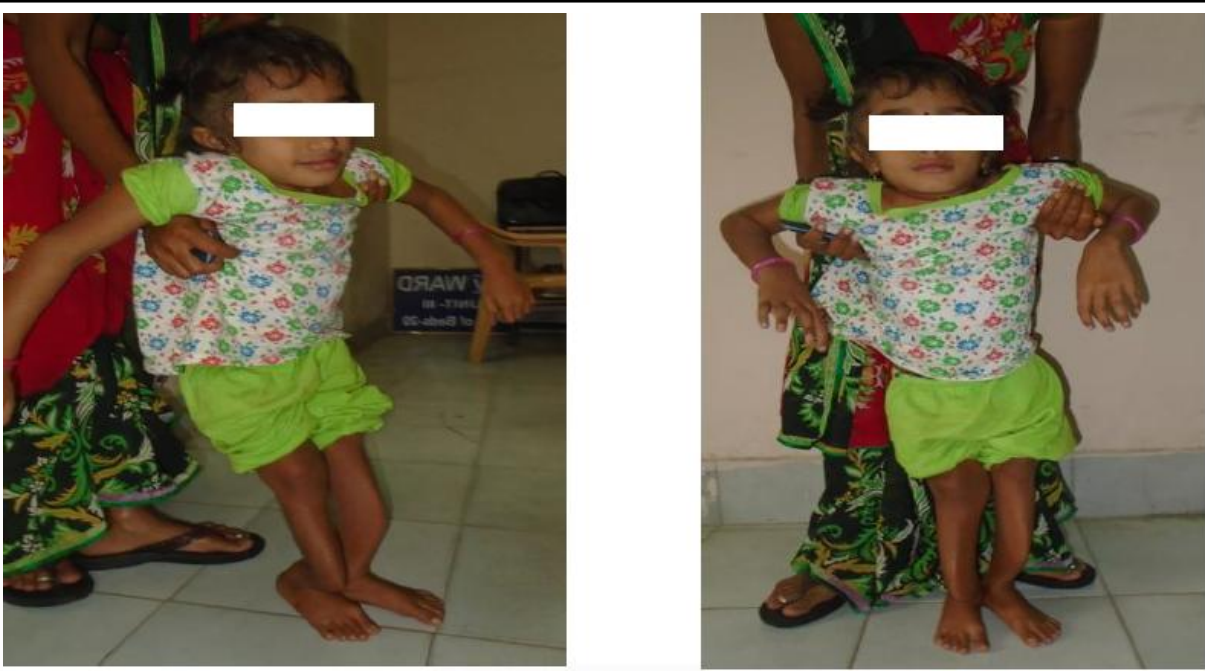

Pre operative Clinical photos of a Case

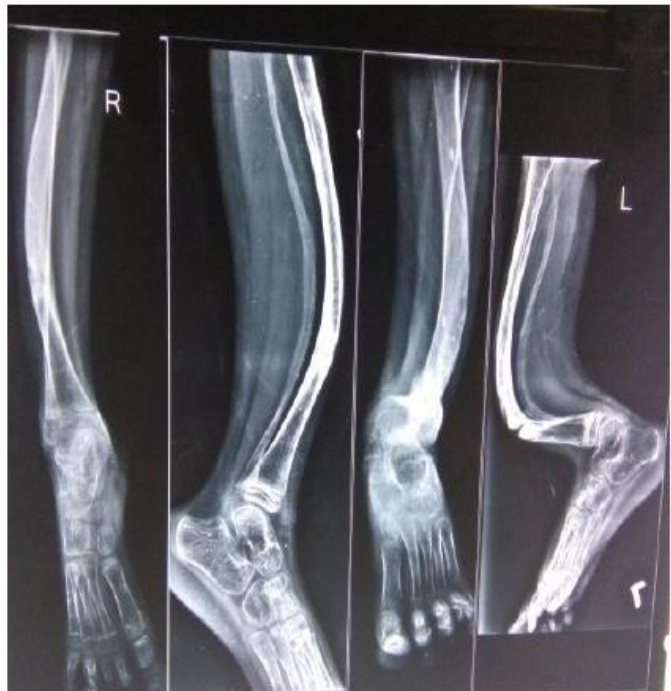

Pre Operative Radiographs

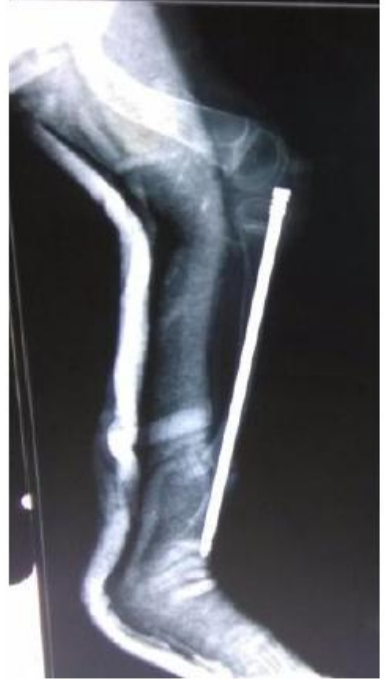

Post Op Radiograph
All surgeries were done under general anaesthesia. Plaster of paris slab immobilization was used postoperatively for each of the surgeries. Post operative rehabilitation included static quadriceps exercises and active toe movements. Post opratively cases were kept under observation in hospital for 5 days and later discharged.

\section{Results}

All Cases were followed up at reggular intervals of 2 weeks, 8 weeks, 4 months and 6 months and 1 year. At 2 weeks after surgery wound status was inspected and suture removal was done. Limb was kept in slab immobilisation for 4 weeks. Later physiotherapy was continued with passive movements and closed chain exercises. At $2^{\text {nd }}$ follow up patient was allowed to partial weight bare with the help of support. Full weight bearing was allowed only after confirmation of radiological healing at 4 months. Later cases were kept under further follow up for any complications. Bisphosphonates were included after 4 months for improvement of bone quality. Osteotomy sites were united successfully without any problems in all 6 cases. Full range of movements are attained in all cases. 5 cases were ambulant without support at 6 months follow up. No wound related complications encountered during this study. One case had recurrence of deformity at the distal tibia after 1 year which was managed by resurgery with osteotomy and application of a new telescopic nail after removal of the implant at the same sitting. 


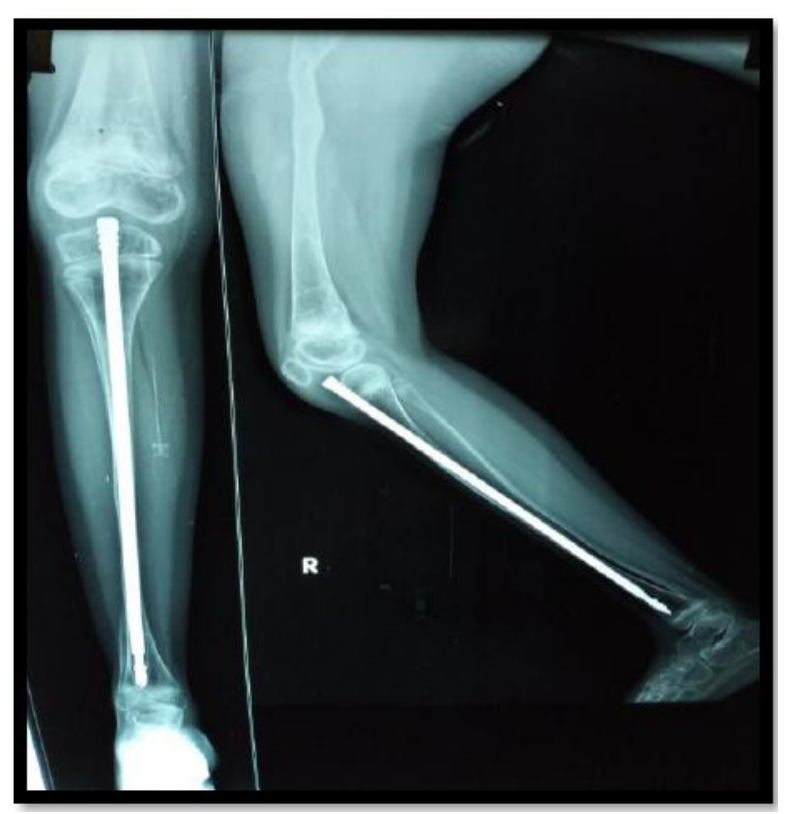

Post operative radiograph at 1year

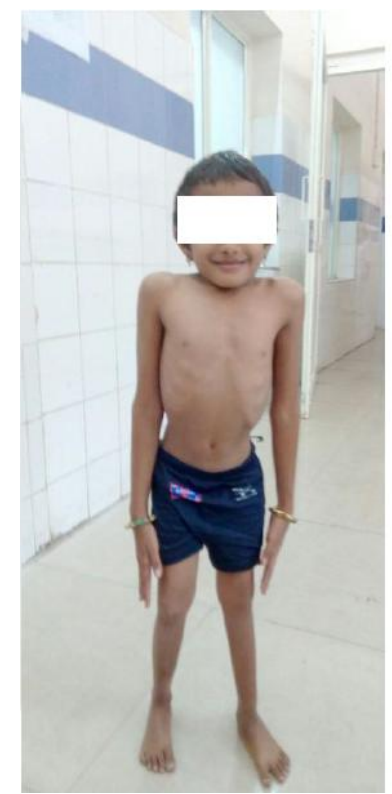

Post Op Clinical Pictures

\section{Conclusion}

Surgical management of deformities in cases of osteogenesis imperfecta is always a challenge. key goal for such a surgery in paediatric patients is ambulation and social integration. Unfortunately such cases are still presenting late. The corrective procedure follows the Soffield -Miller protocol for correction of deformiy and after correction stabilised with telescopic nail. Treatment with bisphosphonates also has an adjuvant effect. By following such a protocol, key goal of ambulation and social integration are achievable and child gets a chance to have a life as close to normal as possible.

\section{References}

1. Glorieux F. Osteogenesis Imperfecta. Best Pract Res Clin Rheumatol. 2008 Mar;22(1):85-100. doi: 10.1016/j.berh.2007.12.012.

2. Forlino A, Cabral WA, Barnes AM,Marini JC. New perspectives on osteogenesis imperfecta. Nat Rev Endocrinol. 2011.doi:10.1038/nrendo.2011.81.

3. Smith R. Osteogenesis imperfecta: from phenotype to genotype and back again.Int J Exp Pathol. 1994; 75:233e41.

4. Birke O, Davies N, Latimer M, Little DG,Bellemore M. Experience with the
Fassier-Duval telescopic rod: first 24c onsecutive cases with a minimum of 1year follow-up. J Pediatr Orthop. 2011Jun; 31(4):458-64. doi:10.1097/BPO.0b013e31821bfb50.

5. McKusick VA. Mendelian Inheritance in Man. 9th ed., 1990, Baltimore: JohnsHopkins University Press.

6. King JD, Boblechko WP. Osteogenesisim perfecta: An orthopaedic description and surgical review. J Bone Joint Surg.1971; 53B:72e89.

7. Sillence D. Osteogenesis imperfecta: an expanding panorama of variants. Clin Orthop. 1981; 159:11e25.

8. Bălănescu R, Ulici A, Rosca D, Topor L, Barbu M. Use of minimally invasive (percutaneous) Fassier-Duval telescopic rod on an 8 year old patient with Lobstein disease. Chirurgia (Bucur). 2013 JanFeb;108(1):120-5.

9. Sterian A, Balanescu R, Barbilian A, Ulici A. Osteosynthesis in Osteogenesis Imperfecta, telescopicversus nontelescopic nailing. Journal of Medicine and Life Vol. 8, Issue 4, October-December 2015. 